\title{
Creating contexts for effective home- based care of people living with HIV/AIDS
}

\author{
C Campbell, PhD Social Psychology, London School of Economics and Centre for \\ HIV/AIDS Networking (HIVAN), University of KwaZulu-Natal \\ C Foulis, MA, HIVAN, University of KwaZulu-Natal
}

\section{Abstract}

Home-based care (HBC) plays a vital role in the care of people living with AIISS. Most carers perform their arduous role in adverse conditions. Yet little is known about how to facilitate contexts that maximise the effectiveness of carers. This paper reviews existing research into home-based care in sub-Saharan Africa to highlight gaps in understanding and to outline new conceptual frameworks for future research. Current research identifies multi-level factors that undermine carers in performing their role. These include e.g. lack of knowledge, skills and support - both at the individual and organisational levels; physical and psychological burnout; the destruction of household economies in the face of the demands of care; community stigma and rejection. Research and policy documents repeatedly advocate 'partnerships' or 'linkages' between carers/ patients and more power- ful groupings (locally, nationally and/or internationally) as a solution to these problems. Yet they give no indication as how best to mobilise already over-burdened carers and their terminally ill charges. Furthermore, partnerships between poor communities and more influential groupings and agencies are notoriously difficult to promote and sustain. If partnerships are indeed to play such a key role in supporting carers and their patients, there is an urgent need for systematic research into the effectiveness of various partnership styles and strategies. The concepts of bonding, bridging and linking social capital - within a framework sensitive to the interaction between social capital and poverty - are put forward as a valuable starting point for the development of better understandings of the types of networks and partnerships most likely to support carers and their local communities.

\section{Introduction}

Home-based care (HBC) plays a vital role in the care of millions of AIDS patients in sub-Saharan Africa where overburdened medical and welfare services are overwhelmed by the demands of the epidemic. Most home-based carers are family members or volunteers who receive little or no training or support, performing their arduous roles in adverse conditions. Much remains to be learned about the challenges of promoting community and social contexts that enable home-based carers to effectively care for their patients. This paper examines the existing state of research into $\mathrm{HBC}$ in the interests of identifying the challenges facing researchers who seek to contribute to on-going debates about how best to design and evaluate community interventions in this area.

Grassroots participation, community mobilisation and multisectoral partnerships form articles of faith in responses to HIV/AIDS both in Africa, and world-wide (Beeker, Gray and Raj, 1998, p. 831). However, research by social scientists lags disappointingly behind developments in policy and practice. Much remains to be learned about the different ways in which local community participation has its allegedly beneficial effects on health and on community development, and about factors most likely to promote or hinder such participation by local people. To date little systematic research has been conducted into the evolution, nature and effectiveness of indigenous grassroots responses to the challenges of HIV prevention and AIDS care. The lack of systematic research or conceptual development in this area limits our ability to learn lessons from the current proliferation of varyingly successful and unsuccessful participatory projects in this field.

This paper highlights the urgent need for research into how best to mobilise the participation of local people and appropriate partners (at the local, national and international levels). Such mobilisation is essential for the challenge of promoting the bonding. bridging and linking social capital most likely to enable carers and their local communities ${ }^{1}$ to address three key challenges. The first is the short-term

'In the light of controversies about definitions of the word 'community', we use the term 'local community' to indicate that we are referring to geographically bounded communities. 
challenge of providing effective care. The second is the challenge of lobbying for the recognition of the needs and interests of carers and their patients. The third is the longterm challenge of developing community strengthening strategies which will leave survivors of this devastating epidemic better equipped to face future epidemics, and better placed to reconstruct their life worlds once the personal and social devastation of this one has run its course.

\section{What is Home-Based Care?}

The World Health Organisation (in Department of Health, 2001 a) define $\mathrm{HBC}$ as "the provision of health services by formal and informal caregivers in the home in order to promote, restore and maintain a person's maximum level of comfort, function and health including care towards a dignified death". Care for people with AIDS is hampered by shortages of hospital beds, inadequate numbers of public sector health professionals, lack of resources for treatment and drugs, and the increasing demands of curable conditions on existing hospital care. An additional factor in South Africa has been the ongoing, and necessary, demand of institutional transformation processes following apartheid. These have severely impacted upon and curtailed the implementation capacity of government. This has been particularly apparent in the implementation of AIDS policy (Schneider \& Stein, 2001). As a result, the burden of care has fallen onto individuals, households and communities (Barnett and Whiteside, 2002). Efforts are starting to be made to develop formal support structures for those offering $\mathrm{HBC}$. These remain patchy, however, and the vast majority of home-based carers continue to battle on, under terrific strain and hardship, with little support. The South African government has identified $\mathrm{HBC}$ as a key priority area for development, and released National guidelines for $H B C$ in December 200I (Department of Health, 2001 a). These guidelines provide a very general outline of the values that should inform the organisation and provision of $\mathrm{HBC}$, and the "stakeholders" who should be involved. However, much work remains to be done on how to put these values into practice, and on how to promote effective partnerships between stakeholders with very different skills, needs and interests. Most existing efforts to build formal HBC initiatives are still in their infancy, and are still in the 'trial and error' stages of learning what strategies do and do not work. Whether they like it or not, home-based carers are often forced to deal with the enormous problems of orphaned children. Furthermore, many HBC initiatives appear quite precarious, functioning from hand to mouth, and with little external support.

Johnson, Modiba, Monnakgotla. Muirhead and Schneider (2001) identify various types of community-based care and support for people living with HIV/AIDS. Three are relevant to our interests in this paper. Firstly there are home visiting programmes which mobilise volunteers to visit AIDS patients in their homes, educating carers and family members about basic care issues, assisting with household chores, accompanying patients to medical appointments and providing psychological support. Secondly there are comprehensive HBC programmes. These are often administered by professionally trained staff - and involve educating family members in palliative care, and linking them to referral networks of health facilities and welfare agencies. The third is where family members care for dying relatives by default, in the absence of any training or support. These approaches draw on an array of actors, ranging from (i) well-trained health care para-professionals, to (ii) volunteers with a mix of formal and practical training - or volun teers with lower levels of formal training who visit the homes of carers and patients, to (iii) untrained lay people operating in isolation, and out of the context of any support initiative.

\section{Health, community and participation}

In the international health promotion literature, three forms of participation are identified as important for promoting health and well-being. The first is grassroots participation in the delivery of formal health services. The degree of access to clinics and hospitals, and the quality of formal health care received by members of minority or marginalised groupings is often hindered by factors such as prejudice, communication difficulties and cultural differences. It is argued that the participation of marginalised group members in the planning and delivery of health care has the potential to undermine such problems (McLean, Campbell and Cornish, 2003). The second is the participation of local people in community-based public health projects designed to promote health-enhancing behaviours (Campbell and MacPhail, 2002). Such participation is believed to impact on health in a range of ways. Firstly it is argued that people are most likely to perform healthy behaviours (e.g. condom use, the appropriate accessing of health services with STIs) if they see that liked and trusted peers are doing so. This assumption is based on the insight that sexual behaviour is determined by social norms as much as by individual decisions (Campbell, 2003). Furthermore, grassroots participation in local health projects may increase people's sense of perceived self-efficacy or empowerment, increasing the likelihood that they will feel that they can take control of their health (Wallerstein, 1992).

Finally, and more indirectly, it is increasingly argued that health and well-being are likely to be enhanced in communities with high levels of social capital, characterised by high levels of grassroots involvement in local community organisations and groupings (Baum, 1999; Blaxter, 2000);

In academic discussions, it is often argued that 'community' is better defined as 'community of interest' than 'community of place'. However, for reasons related to pragmatism and resources, health-related community development projects usually focus their energies on geographically bounded spaces. 
Campbell, 2000; Kawachi, Kennedy, Lochner and ProthrowStith. 1997; Martin, Rogers, Cook and Joseph, 2004; ). Communities with high levels of local participation are said to provide their members with the increased likelihood of health-enhancing social support (Berkman, 1995; Yen and Syme, 1999), and the reduction of health-damaging stress and anxiety (Wilkinson, 1999).

Research in both South Africa (Campbell, Williams and Gilgen, 2002) and Zimbabwe (Gregson, Terceira, Mushati, Nyamukapa and Campbell, 2004) has shown that participation in certain local organisations (particularly women's groups, youth groups and sports groups) protects people against HIV infection, for example. Furthermore, as discussed below, the mobilisation of local people in strong collaborative networks may form a starting point for channels through which local people can lobby support from more powerful actors in the political and economic spheres.

In principle, $\mathrm{HBC}$ has the potential to incorporate all three forms of participation. Firstly, in the terminal stages of AIDS, little specialist hospital care can be given to patients in low-income countries where access to drugs and conventional medical treatments are restricted. In such settings, given appropriate training and support, lay people are able to offer adequate rudimentary nursing skills. Most patients prefer to die with dignity in the familiar surroundings of home, rather than the alien environs of a hospital (Uys, 2003). In such contexts, HBC could be said to offer the environment most appropriate to the dying patient's needs. Secondly, in the light of increasing arguments for the close link between the provision of adequate AIDS care and the success of HIV prevention, it is argued that home based care provides a useful catalyst for counselling and education about HIV/AIDS amongst local families and communities. This is important in the face of patchy levels of knowledge about HIV/AIDS in some communities, and the stigma, rejection and isolation suffered by so many people living with HIV/AIDS. Caring for dying people in communities rather than in more isolated hospital settings promotes first hand awareness of the dangers and effects of HIV/AIDS, which some have argued played an important role in reducing HIV transmission in Uganda (Low-Beer and Stoneburner, 2003). It could also potentially encourage acceptance of AIDS patients in the community, through educating people that HIV is not transmitted by ordinary household contact such as sharing cups or touching.

Thirdly, in an ideal situation, local networks of home-based carers could serve as channels for mobilising local people to lobby for the interests of people living with AIDS not only at the local community level, but also through regional and national structures. Ideally, such mobilisation would enable local people to exert an influence on wider government policies and interventions. It would also generate a community solidarity, which might strengthen communities' abilities to address other challenges to their health and well-being. Small pockets of local participation (such as groups of home-based carers working in a small and geographically isolated area) may form the basis of wider social movements through which otherwise marginalised people might access the ears of more powerful social actors in articulating their needs and interests (Freire, 1973). The potential importance of such links is increasingly appreciated in the growing emphasis on the role of 'partnerships' in discussions about how to strengthen communities to deal with the HIV/AIDS epidemic (Campbell, 2003).

Why this interest in partnerships? An epidemic such as HIV/AIDS is an extraordinary event, arising because existing health facilities and social services are inadequate to manage it. Such a situation presents health workers with the challenge of working to create new and more effective systems of disease prevention and health care that address the extraordinary features of the epidemic. It is now wellrecognised that the prevention of HIV and management of AIDS involve a series of multi-faceted social processes which are beyond the control of individual stakeholder groups in affected communities. (In this paper, the term 'stakeholders' is used to refer to the diverse interest groups that live, work or have some form of stake or interest in the well-being of a particular geographically demarcated community. These might include representatives of women's groups or youth groups, of provincial and national health departments, of foreign-funded NGOs and so on.) Based on the principle that "the whole is greater than the sum of the parts", multi-stakeholder approaches seek to combine the resources and insights of as wide a range of constituencies as possible in tackling epidemics in particular local settings. Such concepts emphasise the importance of the collaboration of grassroots local community members, local and national government health and welfare departments and non-governmental organisations, often with overseas funders.

\section{Empirical research into HBC}

The focus of this section of the paper is the peer-reviewed academic literature on HBC in sub-Saharan Africa. This review drew on three indices, combining the search word 'AIDS' with ('home' and 'care') or ('HBC' or 'home based care'): (i) PubMed/MEDLINE, (ii) the International Bibliography of the Social Sciences and (iii) Abstracts from the 2002 International AIDS Conference in Barcelona. A selected overview of this literature is provided below, to highlight important themes and areas where future research is needed.

Most studies on HBC in sub-Saharan Africa have been done in Tanzania, Uganda, Zimbabwe, Zambia, Botswana, Malawi and South Africa. Most are descriptive in nature. As will be discussed below, this literature is both conceptually and methodologically fragmented. However, a number of common themes cut across the array of articles. Most relate in some way to the strain and hardship facing carers, and the challenges of creating individual, family, household, community and social contexts that enable rather than hinder them from performing their role. Each of these levels of analysis is discussed in turn. 


\section{Individuals}

At the individual level, various studies highlight how carers are hindered by lack of knowledge about how to deliver care in the most effective way. Thus, for example, a Malawian study highlights how carers of children with AIDS often waste time and resources by needlessly seeking hospital treatment for management of minor ailments which can be treated at home (Zimba and McInerney, 2001). Authors emphasise the need to adequately prepare carers for their role - and to ensure regular home visits to reinforce the knowledge they have, and to fill any gaps. A South African study highlights how home-based carers experience considerably more stress and distress than medical carers, in the absence of adequate training, mentoring and support (Wainwright. 2002). Many studies point to the way in which carers are undermined by the traumatic physical and psychological effects of caring for dying people, including burnout and exhaustion (Lindsey, Hirschfield and Tlou, 2(0)3). Lack of knowledge about pain control emerged as a key burden for carers in a multi-country study (Harding, Stewart, Marconi, O'Neill and Higginson, 2003) A Ugandan study pointed to the strong emotional challenges facing carers of children with AIDS, who might already have witnessed their parents fal! sick, become incapacitated, lose their jobs, become stigmatised, and die (Sayson and Meya, 2(0)1).

A Tanzanian study highlighted how caring for an AIDS patient in the terminal stages required between 3 and 7 hours a day in patient care-related activities alone (Nnko, Chiduo, Wilson, Msuya, and Mwaluko, 2000). It also referred to the immense challenges of nursing needy and sometimes difficult dying patients - some of whom may have had diahorrea up to 15 to 20 times a day, in situations where water had to be carried from some distance, and bed linen was a luxury. One carer said her patient was so abusive that relatives advised her to abandon him altogether. Another spoke of her stress when her dying patient repeatedly begged her to adopt her three children after her death. The fact that she was unable to make this promise was a source of distress both to the carer and to the dying patient.

\section{Households}

It is is nearly always women, including young girls, that carry the heaviest burden of care. A Zambian study described women as suffering from "unspeakable physical exhaustion, mental strain, economic hardship and emotional and social deprivation" (Chabinga, 2002). At the household level, a Ugandan study highlighted how the demands of care detracted from women's capacities to fulfil other vital household roles, such as agriculture and other forms of income generation, and non-AIDS related caring duties, particularly in female-headed households (Taylor, Seeley and Kajura, 1996). A pioneering study in Malawi has had some success in mobilising men as volunteer home-based carers, although the authors emphasise that many challenges remain (Bacon, Kukhala, Kaphera and Mgori, 2002). A UNAIDS (2000) report points out that children may be the least acknowledged carers of terminal AIDS patients.
This is backed up by studies in Zimbabwe (Robson, 2000) and Botswana, where Lindsey, Hirschfield and Tlou (2003) report that young girls in caring roles often miss school with some reporting depression, social isolation and sexual abuse. When one parent dies in a nuclear family, there is often no one besides children to look after the other parent who falls sick.

A Tanzanian study of the impact of HIV/AIDS on rural livelihoods was cynical about the romanticised way in which the concepts of 'household and community resources' and 'household and community coping strategies' are used in talking about AIDS care (Rugalema, 20(0)). It argues that this masks the way in which many rural households may be completely destroyed by the social, economic and personal demands of caring for an AIDS patient. Households are often forced to 'cope' by curtailing food consumption, withdrawing children from school (to save money, or free children to help with caring responsibilities), and selling vital survival assets such as livestock or even land. Such shortterm coping strategies often have long-term costs that jeopardise household recovery once the patient has died. Rugalema observes that the use of concepts such as 'community resources' and 'local assets' serve as an excuse by governments and development agencies to do nothing or too little to alleviate the epidemic's effects on impoverished carers, households and communities.

\section{Family}

A South African study warns that 'extended family' models of care and support developed in other countries in the region might not be automatically transferable to South African communities still marked by the disruption and community conflict which characterised the apartheid years (Russell and Schneider, 2000). Apart from this study, the published literature on $\mathrm{HBC}$ in sub-Saharan Africa makes little reference to the family level of analysis. However, a study from India argues that the effectiveness of $\mathrm{HBC}$ is influenced by pre-existing patterns of support and discord within the family. Bharat (1999) shows that people living with HIV/AIDS were treated more positively in families with high trust and low inter-spousal conflict. She concludes that interventions might need to be tailored differently in contexts where household and family responses are positive or negative.

\section{Community}

At the community level of analysis, several studies highlighted how the home-based carer's task is undermined by the stigmatisation of people living with HIV/AIDS (Campbell, Foulis, Maimane and Sibiya, 2004). This severely hinders the support patients and carers get from the community, and leads many patients to extract promises of confidentiality from their carers, or to attempt to hide the nature of their illness from their carers altogether (Maimane, 2004). A South African study (Russell and Schneider, 2000) highlights how carers often feel undermined by their obligation to maintain the confidentiality of their patient's diagnosis. One volunteer cited her despair at seeing the husband of one of her deceased AIDS patients having unpro- 
tected sex with numerous women after his wife had died, and not being able to warn his sexual partners. Another spoke of the tensions around having to lie about why she visited certain families so frequently, or how to explain why she devoted all her attention to only one patient (the AIDS sufferer), in houses where there were also other (non-AIDS) sick or disabled people. Confidentiality of service provision also meant that other community members with HIV/ AIDS were not always aware that care and support were available.

Also criticising romanticised notions of "unswerving community support" for the enterprise of $\mathrm{HBC}$, a Kenyan study describes community attitudes to carers and their patients as ranging from ambivalence to outright rejection (Olenja, 1999). This study also echoes the frequently mentioned theme in the literature of how poverty undermines the possibility of effective care, even amongst individuals or families who are highly motivated to offer it (see also Uys, 2002 for a South African study).

The conditions of abject poverty in which many carers and patients are located prompt a number of articles to highlight the irony and possibly even futility of emphasising AIDS-related para-medical care in homes and communities which lack access to basics for survival, such as food and water. In the context of the threatening famine in many subSaharan African countries this becomes an increasingly pertinent point. In South Africa alone it is estimated that 22-million people could be in danger of starvation (Mametse, Moalusi and Groenewald, 2002). This issue has emerged, for example, in the debates about whether or not it will be possible for HAART drug therapies to be effectively delivered in $\mathrm{HBC}$ settings, when these become more widely available in Africa. A Kenyan study comments cynically on current debates about increasing access to HAART, arguing that in conditions of abject poverty, even if drugs are issued for free, many people living with HIV/AIDS will die of hunger irrespective of the availability of the drugs (Ogutu, 2002).

Not all authors share this despair and cynicism about the limitations of impoverished communities and their members to alleviate suffering. Some are more optimistic about the possibilities of administering successful drug treatment in impoverished settings. A Kenyan study reports on the success of a HBC programme in a slum setting in Nairobi (Obwogo, 2002), where drugs were successfully administered without expensive laboratory backups, using simple monitoring techniques. Obwogo emphasises the key role played by excellent co-ordination between family, community and doctors from the local teaching hospital in the success of this project. In Zambia, Miti, Mfungwe, Riejer and Maher (2003) report on a home-based care programme which successfully integrated directly observed treatment for tuberculosis (DOTS) with home-based care for AIDS patients.

Many studies recommend the need for income generation schemes for carers and their households - given that many of their problems are caused by poverty. However, refer- ences to income generation schemes are usually made at the level of recommendations for the future. Few studies report on the challenges or effectiveness of schemes that have already been implemented in the context of HIV/AIDS management programmes. Two exceptions here are South African studies. The first reports on a futile attempt by an HIV-prevention programme to implement income-generating schemes amongst commercial sex workers to reduce their economic dependence on condom-averse clients (Campbell, 2003). At first sex workers politely collaborated with community workers' attempts to involve them in schemes such as selling vegetables and running crèches for local children. However, after some months, women patiently pointed out that the money that they could make from sex work far exceeded the money they could make from attempting to run small businesses in over-crowded impoverished communities where scant commercial opportunities had generally already been fully exploited. Another South African study (Russell and Schneider, 2000) observed income-generating projects run by a number of $\mathrm{HBC}$ groupings. They reported that more often than not, such projects were not profitable, and that programme participants become frustrated and demoralised. Project workers pointed out that their training in social work or community health did not equip them to run profitable businesses. Without the assistance of business experts they felt that their unsuccessful efforts often simply wasted time, and raised false expectations amongst participants. Much scope remains for exploring the development of partnerships between projects and experienced business people in local communities.

\section{Community/social: partnerships/ collaboration}

At the community and social levels of analysis, few articles did not allude, directly or indirectly, to the importance of co-ordinating appropriate stakeholders, and to the vital role played by various 'linkages' and 'partnerships' in the success or failure of local community efforts to implement $\mathrm{HBC}$ programmes. This emphasis emerged repeatedly through emphases on, for example: the importance of "harmonising" relationships between communities, donors and policymakers (Sagasi, Seroney and Biama, 2002), enhancing collaboration between donor agencies and governments (Harding et al., 2003), establishing strong referral networks between home-based carers and agencies, and building local and international alliances (Wangila, Wafula and Mukhwana, 2002), strengthening the networks available to support carers (Robson, 2000), building links between formal and informal health care systems (Krauthamer, Wong and Coppock, 2002), establishing a good network of informed partners to support carers (Uys, 2001), and facilitating government involvement in care through clarifying the respective tasks of government and other partners such as missionaries and NGOs (Nsutebu, Walley, Mataka and Simon, 2001). Russell and Schneịder's (2000) rapid appraisal of $\mathrm{HBC}$ programmes in South Africa highlight managerial capacity, effective partnerships and referral relationships, and high levels of community cohesiveness as the three hallmarks of successful programmes. However, whilst the 
importance of such links is emphasised repeatedly, there is little in-depth analysis of how best to go about establishing such links, or of the difficulties and challenges facing the task of partnership building.

Much work remains to be done on the potential contribution of traditional healers to the home and community care of AIISS patients. In South Africa, for example, it has been estimated that there are 300000 triditional healers, as opposed to about 20000 biomedical practitioners (Rogerson, 20(12). About $70 \%$ of all South Africans consult a traditional healer at some stage of their lives. A recent study in a South African mining community found a number of traditional healers who were actively collaborating with biomedical health workers on an HIV prevention project. and who had high levels of knowledge about HIV/AIDS (MacPhail, Campell and Pitts, 20(2). These authors argue that traditional healers have a key role to play in supporting people living with AIDS, including providing them with advice about nutrition, and psychological support. A recent study by Colvin, Gumede, Grimwade, Maher and Wilkinson (2(0)2), also in South Africa, outlines a very successful venture in which healers collaborated with biomedical health workers in the successful implementation of home-based drug therapy for tuberculosis patients. However, the mining community study referred to above also identified healers who claimed they could cure HIVIAIDS, and who had very low levels of relevant knowledge. A study in Botswana (Chipfakacha, 1997) identitied a number of traditional healer practices that potentially placed both healers and patients at risk. Experienced home-based carers of terminally ill AIDS patients in Tanzania told researchers that a key lesson they would seek to pass on to inexperienced carers was not to waste time, money or dashed hopes on seeking traditional healer treatment (Nnko et al., 2000). Whatever the merits and demerits of traditional healers, however, the reality is that they are a very important source of health care in subSaharan Africa. They need to be included as key stakeholders in $\mathrm{HBC}$ projects, and much work remains to be done in exploring possibilities for traditional-biomedical collaboration.

This section has provided a thumbnail overview of the academic literature on $\mathrm{HBC}$. Whilst it contains many useful insights, most articles report on descriptive case studies, focusing narrowly on particular micro-contexts, conducted out of the context of any academic disciplinary background or theoretical framework. There is a pressing need to develop conceptual frameworks that begin to systematise and pull together the myriad of useful insights. Practically, such systematisation would help to make the array of insights accessible to those engaged in designing and evaluating $\mathrm{HBC}$ policies and interventions, who do not necessarily have the time or resources to warle through hundreds of studies. At the theoretical level, there is an urgent need for the development of more holistic conceptual frameworks to integrate the multi-level insights represented in this fragmented body of literature in order to point to areas where further research is needed. In the world of HIV-prevention/ AIDS-care policy and practice, there is now general acceptance of a social view of health. Such a view, which increasingly informs the design of policy and intervention, acknowledges the importance of including attention to the biomedical. behavioural and social dimensions of human experience in seeking to promote HIV-prevention or AIDS care and management. In the world of AIDS researc $h$, however, there is often a tendency for researchers to pay lip service to holistic understandings of health in the introductions and conclusions of papers. However they then focus their attention exclusively on one level of analysis in their research designs and presentation of findings (be it the psychological, or the household, for example). Little or no indication is given of how their particular findings might interface with other levels of analysis within a more holistic framework.

The most striking example of this in the literature on $\mathrm{HBC}$ is the frequency with which authors refer to the importance of partnerships between local communities and other actors and agencies (varyingly drawn from civil society, public sector or private sector - at the local, national or international levels). This emphasis is consistent with the international public health literature on participation and health outlined above. However, there is little attention to three vital issues. Firstly little attention is given to the processes and mechanisms whereby such partnerships have the potential to impact on peoples' physical and psychological health and well-being. The link between partnerships and health is simply assumed, rather than problematised and explicated. Secondly little attention is given to the complexities of implementing collaborative partnerships between constituencies who may have very different needs and interests, and very different motivations for their interest in HBC (e.g. women in impoverished rural households, local private sector representatives, and national health policy-makers). Finally, little attention is given to the complexities of mobilising already over-burdened carers and their terminally ill charges, or to methods for ensuring their representation by advocates who adequately understand their needs and interests.

\section{Conceptualising partnerships and alliances: bonding, bridging and linking social capital}

Above it has been argued that whilst research has gone a long way in identifying challenges facing home-based carers, and indicating the types of support they need, much remains to be learned about the conmunity and social contexts most likely to provide them with this support. Both research and policy documents make frequent reference to the vital role of 'partnerships' in creating such contexts. Ideally such partnerships form the basis for collaboration between disadvantaged communities and more influential groupings and agencies that have the powe: to assist them 
in achieving their goals (Gillies, 1998). Yet a large international development studies research literature points to the immense difficulties of promoting and sustaining such partnerships. Much work remains to be done in exploring the gap between the rhetoric and reality of multi-stakeholder collaboration, and in understanding factors that promote or hinder the implementation of theoretically and politically sound policy prescriptions.

A recent study of a multi-sectoral partnership created to manage a large and well-resourced HIV-prevention programme in a South African mining community highlighted a myriad of factors which undermined collaboration between partners drawn from grassroots communities, provincial and national government, trade unions, mining houses and researchers (Campbell, 2003). These included lack of common understanding of the problem of HIV/AIDS and how to solve it; lack of health systems expertise to synthesise the talents and contributions of such a diverse range of constituencies; the dominance of a biomedical model of discase control over more social perspectives which meant that powerful hiomedical actors often didn't have adequate understanding of the rationale for partnerships: varying levels of commitment and motivation by different groups of players; and inadequate incentives/ systems of accountability to motivate more powerful groupings to participate in assisting less powerful ones.

If partnerships are indeed to play such a key role in supporting carers and their patients, there is an urgent need for systematic research into the types of relationships and alliances best suited to performing this role, as well as the identification of factors most likely to promote or hinder their success. The concept of 'social capital' is increasingly being cited in debates about what constitutes a healthenabling community context, and provides a useful starting point for this task (Blaxter, 20(0); Cambpell, 20(0)). According to the social capital perspective, people are most likely to be healthy in communities characterised by high levels of trust, reciprocal help and support, positive local identities and participation in informal and formal social networks and organisations (Baum, 1999). Kreuter (cited in Campbell, 2003) defines social capital as "those specific processes among people and organisations, working collaboratively and in an atmosphere of trust, that lead to the accomplishment of goals of mutual social benefit". Social capital researchers are concerned to examine the role of (i) informal and formal social networks; and (ii) norms of cooperation in promoting local community development. They examine the way in which these norms and networks operate both within a local community, and in its relationship to outside networks and institutions.

Applying the social capital framework to the HIV/AIDS field, our starting assumption would be the belief that within constraints of poverty, stigma and gender inequalities, residents of marginalised communities are able to act collectively to improve their circumstances. However the extent to which this collective action is effective depends heavily on the quality of the alliances that poor people are able to form with groupings who have greater access to material resources and political influence. The unequal distribution of social capital is one of the key mechanisms whereby poverty is perpetuated, and whereby poor people are hindered from improving their life circumstances (Bourdieu, 1986). Building social capital thus becomes a key challenge for those seeking to work with poor people to improve the life circumstances that make them particularly vulnerable to HIV/AIDS, and which hinder them in their efforts to support people living with AIISS.

Sategert. Warren and Thompson (20)1 ) distinguish between three forms of social capital - which are relevant to the types of relationships most likely to facilitate $\mathrm{HBC}$ (see also Woolcock, 1998). The first of these is bonding social capital, which refers to relationships of trust, reciprocity and positive common identity within homogenous groups. This is the kind of social capital that would result from the development of close-knit groups of women involved in HBC within a particular local community. Such networks would provide women with vital sources of social support and advice from others battling with similar challenges in similar local community contexts. However, given that many carers' problems result from lack of access to various material resources, as well as lack of specialist expertise and skills which they may not have themselves, a wider series of linkages and relationships is needed to support them in achieving their goals. These are the linkages inherent in bridging and linking social capital.

Bridging social capital refers to four different sorts of relationships. The first are bridging relationships across different groups within particular geographical communities. An example of this might include relationships between a groups of carers on the one hand, and local women's, church or youth groups on the other hand. The second refers to relationships between groups in different low income communities. These might include the development of networks of solidarity between groups of carers from different geographical communities. The third refers to links between poor and more affluent communities. These might include links between local carers groups and women's or church groups from more affluent areas. The fourth refers to networks which link the three kinds of networks referred to above at a national level.

Linking social capital refers to linkages between local community residents and representatives of mainstream economic and political institutions. Researchers have coined the term 'synergy' to characterise a situation where grassroots community groupings, economic actors and state institutions work together for positive developmental outcomes (Woolcock, 1998). In relation to economic actors, alliances between community groupings, and local businesses or employers may play a role in the development of income generation schemes for carers, for example. The latter may also contribute funding or donations of food or equipment, to cite another example. Evans (1996) argues that community development projects are said to have the greatest chance of success in conditions of "state-society synergy', where government policies and practices are supportive of the goals of the local project. Ideally, social capital linking together marginalised communities and local or national government networks has the capacity to ensure 
that government actors are aware of the needs and interests of local carers.

What are the areas in which carers need support and assistance? What are the challenges facing participants in the different types of alliances or partnerships discussed above? In the short-term, carers clearly need assistance with the immediate challenges of meeting the physical and emotional needs of their patients. However, at the pragmatic level, their ability to provide effective care is influenced by the community and social contexts within which they are located. Thus, it is argued here that the second challenge facing such alliances is that of assisting carers in lobbying for the recognition of the needs and interests of both their patients and themselves. The latter point is consistent with government policies relating both to primary health care and to HIV/AIDS management, mentioned above. These emphasise not only the narrow needs of patients, but also the importance that care is offered in a supportive social environment, and that activities are planned and managed in ways that strengthen communities' abilities to respond to other health crises in addition to those of HIV/AIDS. Following from this, the third challenge is that of developing local community health networks which not only support carers and their patients, but also have the potential to strengthen communities to cope with other health challenges, as well as face the challenges of reconstructing their social fabric once the epidemic has run its course. Much work remains to be done in:

- $\quad$ examining which forms of social capital have the potential to assist local communities in meeting each of these challenges;

conducting systematic research into the evolution, nature and effectiveness of different partnership strategies; and

- developing understandings of the factors which promote or hinder the success of the different types of alliance/ linkages underlying each type of social capital.

- Increased understandings in these three areas could play a key role in developing understandings of how best to support home-based carers in performing their vital and arduous roles.

\section{Acknowledgements}

Thanks to Professor Eleanor Preston-Whyte, Director of the Centre for HIV/AIDS Networking (HIVAN) for making this research possible. Thanks also to Mrs Debbie Heustice, HIVAN Project Manager. In the course of producing this paper the authors benefited from discussions of the social issues surrounding home-based care with HIVAN colleagues Ms Yugi Nair, Ms Sbongile Maimane and MrZweni Sibiya. Ms Nair also assisted with the production of the manuscript.

\section{References}

BACON, C; KUKHALA, G; KAPHERA, I \& MGORI, E 2002: Mobilising men as home based care volunteers. (Pres- entation at the XIV International AIDS Conference 2002, Barcelona, July 7-12. Abstract number: TuOrF1253.)

BARNETT, T \& WHITESIDE, A 2002: AIDS in the $21^{\text {st }}$ Century: disease and globalisation. London: Palgrave MacMillan.

BAUM, F 1999: Social capital: is it good for your health? Issues for a public health agenda. Journal of Epidemiology and Community Health. 53 (4): 195- 196.

BEEKER, C; GRAY, G \& RAJ, A 1998: Community empowerment paradigm and the primary prevention of HIV/ AIDS. Social Science and Medicine. 46 (7): 831-842.

BERKMAN, L 1995: The role of social relations in health promotion. Psvchosomatic Medicine. 57: 245-254.

BHARAT, S 1999: Facing the challenge: household responses to HIV/AIDS in Mumbai, India. AIDS Care. 11(1): $31-44$.

BLAXTER, M 2000: Medical Sociology at the start of the new millennium, Social Science \& Medicine. 51: $1139-1142$.

BOURDIEU, P 1986: The forms of capital. (In: Richardson, $\mathrm{J} \mathrm{Ed}$. Handbook of theory and research for the sociology of education. New York: Greenwood Press, pp 24 I-248).

CAMPBELL, C 2003: Letting them die: why HIV prevention programmes fail. Cape Town: Juta. / Oxford: James Currey. / Bloomington: Indiana University Press.

CAMPBELL, C 2000: Social capital and health: Contextualising health promotion within local community networks. (In: Baron, S; Field, J. \& Schuller, T Eds. Social capital: critical perspectives. Oxford: Oxford University Press, pp 182-196).

CAMPBELI,C; FOULIS, CA; MAIMANE,S \& SIBIYA,Z 2004: "I have an evil child at my house": stigma and HIV/ AIDS management in a South African community. American Journal of Public Health (forthcoming).

CAMPBELL, C \& MACPHAIL, C 2002: Peer education, gender and the development of critical consciousness: Participatory HIV prevention by South African youth. Social Science and Medicine. 55 (2): 331-345.

CAMPBELL, C; WILLIAMS, B \& GILGEN, D 2002: Is social capital a useful conceptual tool for exploring community level influences on HIV infection? An exploratory case study from South Africa. AIDS-Care, 14(1): 41-55.

CHABINGA, $P$ 2002: Informal care of AIDS patients: the plight of women in Zambia. (Presentation at the XIV International AIDS Conference 2002, Barcelona, July 7-12. Abstract number: ThPe G8342).

CHIPFAKACHA, V 1997: STD/HIV/AIDS knowledge, beliefs and practices of traditional healers in Botswana. 
AIDS Cire. $9(4):$ 417-25.

COLVIN, M; GUMEIE, I ; GRIMWADE, K; MAHER, I) \& WILKINSON, D 2002: Integration of traditional healers into a rural tuberculosis control programme in South Africa. (Presentation at the XIVth International Conference on AIDS in Barcelona, July 7-12. Abstract number: ThPeB7264.)

DEPARTMENT OF HEALTH 2001: National Guidelines on Home-Based Care/ Community-Based Care. http:// 196.36.153.56/doh/docs/facts-f.html

EVANS, P 1996: Government action, social capital and development: reviewing the evidence on synergy. World Development. 24 (6): $1119-1132$.

FREIRE, P 1973: Pedagogy of the oppressed. Harmondsworth: Penguin.

GILLIES, P 1998: Effectiveness of alliances and partnerships for health promotion. Health Promotion International. 13: $1-21$.

GREGSON, S; TERCEIRA, N; MUSHATI, P; NYAMUKAPA, C \& CAMPBELL, C 2004: Community group participation: can it help young women to avoid HIV? An exploratory study of social capital and school education in rural Zimbabwe. Social Science and Medicine. 58: 2119-2132.

HARDING, R; STEWART, K; MARCONI, K; O'NEILI.J \& HIGGINSON, I. 2003: Current HIV/AIDS end-of-life care in sub-Saharan Africa: a survey of models, services, challenges and priorities. BMC Public Health. 3 (33): 28-39.

JOHNSON, S; MODIBA, P; MONNAKGOTLA, D; MUIRHEAD, D \& SCHNEIDER, H 2001: Home-based care for people with HIV/AIDS in South Africa: What will it cost? Johannesburg: Centre for Health Policy, University of Witwatersrand.

KAWACHI, I; KENNEDY, B; WILKINSON, R \& PROTHROW-STITH, D 1997: Social capital, income inequality and mortality. American Journal of Public Health 87: 1491-1498

KRAUTHAMER, M; WONG, I \& COPPOCK, D 2002: Home based care in the rural setting. (Presentation at the XIV International AIDS Conference 2002, Barcelona, July 7-12. Abstract number: WePeF6632.)

IINISEY, E; HIRSCHFELD, M \& TLOU,S 2003: Homebased care in Botswana: experience of older women and young girls. Health Care Women International. 24 (6), 486 5() 1 .

IOW-BEER, D \& STONEBURNER, R 2003: Behaviour and communication change in reducing HIV: is Uganda unique? African Journal of AIDS Research. 3(1): 1-13.

MACPHAIL,C,CAMPBELL, C \& PITTS, M 2014: 'Who can cure AIDS?' The role of traditional healers in diagnosing and treating STIs and HIV/AIDS. Submitted for publication.

MAIMANE,S 2004: The role of volunteer community health workers in AIDS care in a rural setting in South Africa. (Paper to be presented at the XV International AIDS Conference, Bangkok, July 2004).

MAMETSE, I); MOALUSI, R \& GROENEWALD, Y 20)2: SA not immune to famine. Mail and Guardian. July 19 to 25 : 5.

MARTIN, K; ROGERS, IB; COOK, J \& JOSEPH, H 2004: Social capital is associated with decreased risk of hunger. Social Science and Medicine. 58: 2645-2654.

MCIEAN, C; CAMPBELI, C \& CORNISH, F 2003: African-Caribbean interactions with health services: experiences and expectations as (re)productive of health inequalities. Social Science and Medicine. 56: 657-669.

MITI, S; MFUNGWE, V; REIJER,P \& MAHER, D 2003: Integration of tuberculosis treatment in a community-based home care programme for persons living with HIV/AIDS in Ndola, Zambia. International Journal of Tuberculosis and Lung Disease. 7 (9.1): S92-8.

NNKO, S; CHIDUO, B; WILSON, F; MSUYA, W \& MWALUKO, G 2000: Tanzania: AIDS Care - Learning from Experience. Review of African Political Economy. 86 : 547-557.

NSUTEBU, E; WALLEY, J; MATAKA, E \& SIMON, C 2001: Scaling up HIV/AIDS and TB home-based care: lessons from Zambia. Health Policv and Planning. 16 (3): 2407.

OBWOGO, N 2002: Use of anti-retrovirals in a slum-based home care setting: The slum doctor programme model. (Presentation at the XIV International AIDS Conference 2002, Barcelona, July 7-12. Abstract number: WePeF6630)

OGUTU, G 2002: Home Based Care services by Community Based Organisation (CBOs) on HIV/AIDS Program as best solution for decongesting the hospitals. (Presentation at the XIV International AIDS conference 20(02, Barcelona, July 7-12. Abstract number: WePeF6652).

OLENJA, J 1999: Assessing community attitude towards home-based care for people with AIDS (PWAs) in Kenya. Journal of Community Health. 24 (3): 187-99.

ROBSON, E 2000: Invisible carers: young people in $\mathrm{Zim}-$ babwe's home-based healthcare. Area. 32(1): 59-69.

ROGERSON, $R$ 2002: Traditional African healers: their role in the fight against STDs, HIV and AIDS in Southern Africa. (Presentation at the XIV International AIDS Conference 2002, Barcelona, July 7-12. Abstract number: E11522). 
RUGALEMA, G 2000: Coping or struggling? A journey into the impact of HIV/AIDS in Southern Africa. Review of African Political Economy. 86: 527-545.

RUSSELL, M \& SCHNEIDER, H 2000: A rapid appraisal of community based HIV/AIDS care and support programmes in South Africa. Johannesburg: Centre for Health Policy, University of Witwatersrand.

SAEGERT, S; THOMPSON, J \& WARREN, M 2001: Social capital and poor communities. New York: Russell Sage Foundation.

SAGASI, E; SERONEY, I \& BIAMA, P 2002: Priority concerns for HIV/AIDS prevention and control in a rural community. (Presentation at the XIV International AIDS conference 2002, Barcelona, July 7-12. Abstract number:MoPeE3782).

SAYSON, R \& MEYA, A 2001: Strengthening the roles of existing structure by breaking down barriers and building up bridges: intensifying HIV/AIDS awareness, outreach and intervention in Uganda. Child Welfare. 80 (5): 541-50.

SCHNEIDER, H \& STEIN, J 2001: Implementing AIDS policy in post-apartheid South Africa. Social Science and Medicine. 52: 723-731.

TAYLOR, L; SEELEY, J \& KAJURA, E 1996: Informal care for illness in rural southwest Uganda: the central role that women play. Health Transitions Review. 6 (1): 49-56.

UNAIDS 2000: Caring for carers: managing the stress in those who care for people with HIV and AIDS. Geneva: UNAIDS Best Practice Collection.

UYS, L 2001: Evaluation of the Integrated CommunityBased Home Care Model. Curationis. 24 (3): 75-82.

UYS, L 2002: The practice of community caregivers in a home-based HIV/AIDS project in South Africa. Journal of Clinical Nursing. 11 (1): 99-108.

UYS, L 2003: Aspects of the care of people with HIV/ AIDS in South Africa. Public Health Nursing. 20(4): 271280.

UYS, I \& CAMERON, S 2003: Home-based HIV/AIDS care. Cape Town: Oxford University Press.

WAINWRIGHT, A 2002: Participatory home based care and mentoring. (Presentation at the XIV International AIDS Conference 2002, Barcelona, July 7-12. Abstract number: F12249).

WALLLERSTEIN, N 1992: Powerlessness, empowerment and health: implications for health promotion programmes. American Journal of Health Promotion. 6 (3): 197-205.

WANGILA, S; WAFULA, S \& MUKHWANA, K 2002: Sustainability of home-based care and support programs in Western Kenya. (Presentation at the XIV International
AIDS conference 2002, Barcelona, July 7-12. Abstract number: WePeF6620).

WILKINSON, R 1999: Health, hierarchy and social anxiety. Annals of the New York Academv of Sciences. 896: 4863.

WOOLCOCK, M 1998: Social capital and economic development: towards a theoretical synthesis and policy framework. Theorv and society. 27, 151-208.

YEN, I \& SYME, S 1999: The social environment and health: a discussion of the epidemiologic literature. Annual Review of Public Health. 20: 287-308.

ZIMBA, E \& MCINERNEY, P 2001: The knowledge and practices of primary caregivers regarding home-based care of HIV/AIDS children in Blantyre, Malawi. Curationis. 24 (3): 83-9I. 